\title{
Primary human monocyte differentiation regulated by Nigella sativa pressed oil
}

\author{
Mahaya C Mat ${ }^{1}$, Azman S Mohamed ${ }^{2}$ and Shahrul S Hamid ${ }^{2 *}$
}

\begin{abstract}
Background: Oxidized low density lipoprotein plays an important role in development of foam cells in atherosclerosis. The study was focused on regulation of primary human monocyte growth and CD11b expression in presence of Nigella sativa oil.

Methods: Primary human monocytes were isolated from whole blood and grown at $37^{\circ} \mathrm{C}$ and $5 \% \mathrm{CO} 2$ saturation for five days prior to treatment with Nigella sativa oil. The cells were plated and washed before treatment with oxLDL $(10 \mu \mathrm{g} / \mathrm{ml})$ as positive control and combined treatment of ox-LDL $(10 \mu \mathrm{g} / \mathrm{ml})$ and $(140 \mathrm{ng} / \mathrm{ml})$ Nigella sativa oil. The growth progression was monitored every 24 hours for 3 days.

Results: Macrophages showed reduced growth in comparison to monocytes 24 hours after treatment with Nigella sativa oil. The mean cell diameter was significantly different between untreated and treated condition in monocytes and macrophages $(p<0.001)$. Similarly, intracellular lipid accumulation was hindered in combined treatment with Nigella sativa oil. This was further supported by cell surface expression analysis, where CD11b was markedly reduced in cells treated with combination oxLDL and Nigella sativa oil compared to oxLDL alone. More cells differentiated into macrophage-like cells when monocytes were supplemented with oxidized LDL alone.
\end{abstract}

Conclusions: The finding provides preliminary evidence on regulation of cell growth and differentiation in monocyte and monocyte-derived macrophages by Nigella sativa oil. Further investigations need to be conducted to explain its mechanism in human monocyte.

\section{Background}

Coronary artery disease (CAD) has continued to be the leading cause for the world's morbidity and mortality. Similarly, Ministry of Health of Malaysia declared coronary artery disease as the leading cause of hospital admission and non-accidental deaths over the last decade [1]. Data summary from 1994 to 2001 showed heart disease accounted for $14 \%$ to $16 \%$ of the principal cause of death in government hospitals in Malaysia [2].

Atherosclerosis is closely related to development of coronary artery disease [3]. The earliest visible lesion of atherosclerosis is the fatty streak, an aggregation of cholesterol-loaded macrophages or foam cells within the arterial wall [4]. LDL oxidation has been proven to be associated with atherosclerosis and has been regarded as

\footnotetext{
* Correspondence: shahrulbariyah@amdi.usm.edu.my

${ }^{2}$ Advanced Medical and Dental Institute, Universiti Sains Malaysia, Lot 1-8, PersiaranSeksyen 4/1, Bandar Putra Bertam, Kepala Batas 13200, Penang, Malaysia

Full list of author information is available at the end of the article
}

a key step in atherogenesis [5]. Level of circulating oxidized LDL was higher in patients with coronary heart disease [6]. Macrophages will continue the uptake of oxidized LDL via scavenger receptors and further accumulate intracellular cholesterol before transforming into foam cells [7]. Differentiation of monocyte renders the cell ready for active participation in inflammatory and immune responses [8].

Macrophages are key players in many aspects of human physiology and disease [9]. A hallmark of the development of atherosclerotic plaques is the prior and concurrent accumulation in the arterial intima of lipoprotein particles subject to chemical modifications. This is associated with local inflammation in the vessel wall and further recruitment of monocytes from the circulation. By taking up such modified LDL (oxidized or acetylated), monocyte-derived macrophages are turned into fatloaded macrophages residing in the vessel wall and furthering the local inflammatory response. The
C Biomed Central

() 2011 Mat et al; licensee BioMed Central Ltd. This is an Open Access article distributed under the terms of the Creative Commons Attribution License (http://creativecommons.org/licenses/by/2.0), which permits unrestricted use, distribution, and reproduction in any medium, provided the original work is properly cited. 
mechanisms underlying such foam cell generation has for several years been the focus of intensive research [10-14].

An experiment where a culture of monocytes with oxidized LDL, resulted in increased expression of CD14, TLR-4 ( $\mathrm{p}<0.001$ ), there were as well as increased production of inflammatory mediators such as IL-6, IL-1 $\beta$, and at a lower extent, TNF- $\alpha$ and MCP-1 factors [15]. It was evidenced that there was progressive increase in cellular size, density, granulation and expression of surface markers CD11b and CD36 during macrophage maturation [16]. In un-stimulated monocytes and granulocytes, CD11b are present in an intracellular, vesicular compartment, as well as on the cell surface. Inflammatory mediators were found to stimulate a 5 to 10 fold increase in Mac-1 (CD11b) and p150,95 on the cell surface $[17,18]$. Oxidized LDL and minimally modified LDL increased CD11b expression, suggesting the role CD11b for enhanced monocyte adhesion and this was demonstrated by prevention of monocyte adhesion by using anti-CD11b mAb [19].

The development of natural product has been drawing attention towards this treatment modality. Numerous studies have addressed the potential use of natural products. In Southern Asia and Middle East Asia for centuries, Nigella sativa L seed has been used to treat numerous diseases. More than 25\% of drugs used during the last 20 years are directly derived from plants, while the other $25 \%$ are chemically altered natural products [20]. Studies have shown that the seed and oil exert very low degree of toxicity [21]. The chemical composition include 32-40\% fixed oil, $0.4-0.45 \% \%$ volatile oil, proteins, alkaloids, coumarins, saponins, minerals, carbohydrate and fiber [22-24]. The volatile oil contain $18.4-24 \%$ thymoquinone and $46 \%$ of monoterpenes such as $\rho$-cymene and $\alpha$-piene [23]. ElBahai et al. reported evidence of physiological and beneficial cardiac hypertrophy in rats induced by long term Nigella sativa supplementation [25]. There are also studies that have shown its promising anti-cancer effects in animal model [24]. Recent data directly implicate signaling by TLR4 in the pathogenesis of atherosclerosis, establishing a key link between atherosclerosis and defense against both foreign pathogens and endogenously generated inflammatory ligands [26]. The critical role of modified LDL in atherogenesis suggests the need to control its progression. Therefore, modulatory effect of Nigella sativa oil on the progression of monocyte-derived macrophage growth was investigated.

Nigella sativa was found to exerts its effects via suppressing productions of IL- 6 , TNF- $\alpha$ and NO, key pro-inflammatory mediators by primary macrophages, as shown in an experiment done using Nigella sativa aqueous extract [27]. Nigella sativa contains thymoquinone which has been reported as a potent anti-inflammatory and cytoprotective agent [28]. It also has been documented that thymoquinone is major bioactive component of Nigella sativa to upregulate expression of hepatocyte LDL receptor gene and suppress activation of HMG-CoA receptor [29]. However, it was found that thymoquinone-rich fraction extract showed higher activity compared to pure thymoquinone due to multiple bioactive compounds that work synergistically [30].

\section{Results}

Isolation and identification of primary human monocytes The cells isolated using MyPureDynabeadswere cultured in RPMI 1640 medium for growth. Images of primary monocytes isolated were captured using phase contrast microscope Axiovert 25 (ZEISS) as shown in Figure 1. The isolated monocytes were identified using Wright's stain smear and visualized under light microscope at $400 \times$ magnification. The cells were stained in blue and had kidney-shaped single nucleus with light blue shaded cytoplasm. Figure 2 shows monocyte under light microscope at $400 \times$ magnification.

The oil red $\mathrm{O}$ stain was used to identify vesicles that contain mainly cholesterol esters in the primary monocytes. Comparison of lipid accumulation between untreated cells and treated cells showed differences in the staining area. Figure 3 showed positive staining in monocytes following treatment with oxidized LDL. However, addition of Nigella sativa oil led to inhibited cell growth and impaired accumulation of oxidized LDL evidenced by the reduced intracellular staining in treated cells (Figure 4). The cells that were not exposed to either oxidized LDL or combination of oxidized LDL and Nigella sativa oil were seen to grow larger than those treated with combination of oxidized LDL and Nigella sativa but had small vesicles stained with oil red O (Figure 5).

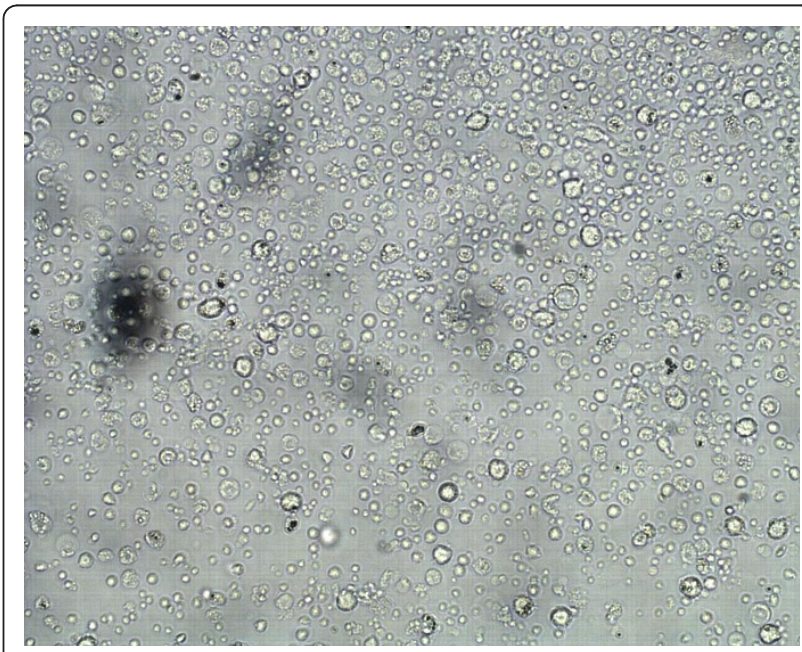

Figure 1 Primary monocytes following isolation using magnetic Dynabeads under 100× phase-contrast microscope. 


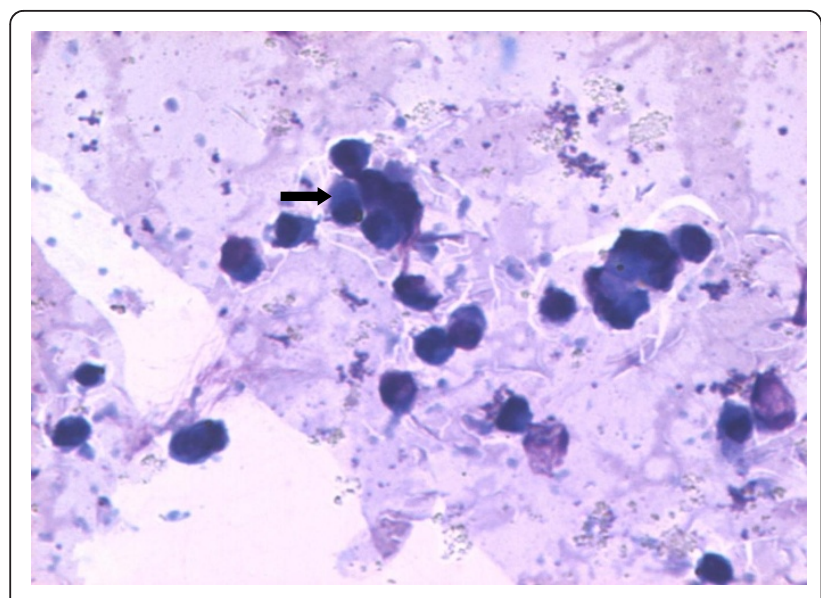

Figure 2 The arrow indicates primary monocytes stained with Wright's stain visualized under $400 \times$ light microscope.

\section{Percentage of Nigella sativa oil dilution}

From the trypan blue dye cell exclusion method, the percentage of viable cells was more than $90 \%$ with 140 $\mathrm{ng} / \mathrm{ml}$ Nigella sativa oil. The $\mathrm{IC}_{50}$ value obtained in this study was $180 \mathrm{ng} / \mathrm{ml}$.

\section{Effects of Nigella sativa on oxidized LDL uptake by monocytes and macrophages}

Monocytes/macrophages were grown in RPMI media for 5 days prior to addition of $10 \mathrm{ug} / \mathrm{ml}$ oxLDL or combination of $10 \mu \mathrm{g} / \mathrm{ml}$ oxidized LDL with $140 \mathrm{ng} / \mathrm{ml}$ Nigella sativa oil. The cells used as control untreated and treatment involved supplementation of oxidized LDL and Nigella sativa oil. These cells were left to grow in 5\% $\mathrm{CO}_{2}$ at $37^{\circ} \mathrm{C}$. The untreated cell growth was captured using $40 \times$ phase-contrast microscope at every 24 hours interval for 3 days as shown in Figure 6, 7, and 8,

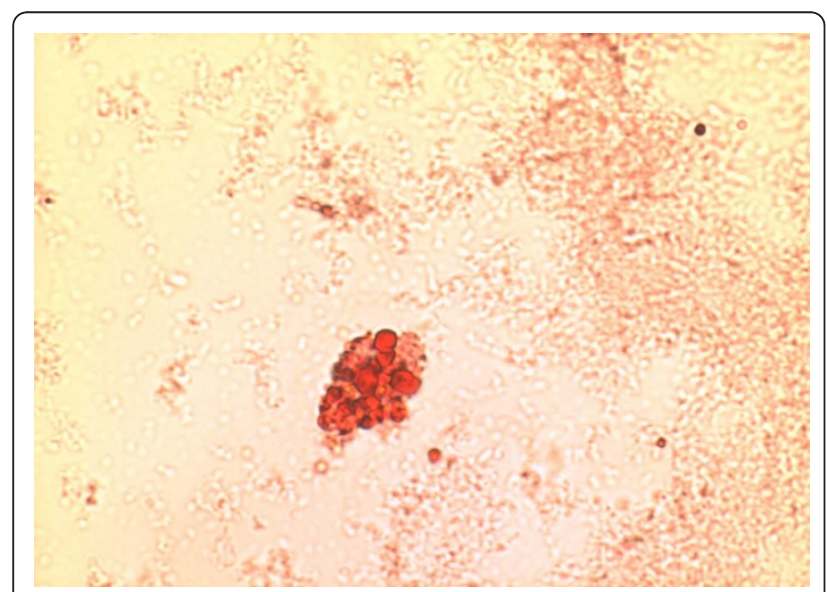

Figure 3 Monocytes-derived macrophages at day 3 posttreatment with oxidized $L D L$, stained with oil red $O$ stain and visualized under $400 \times$ light microscope.

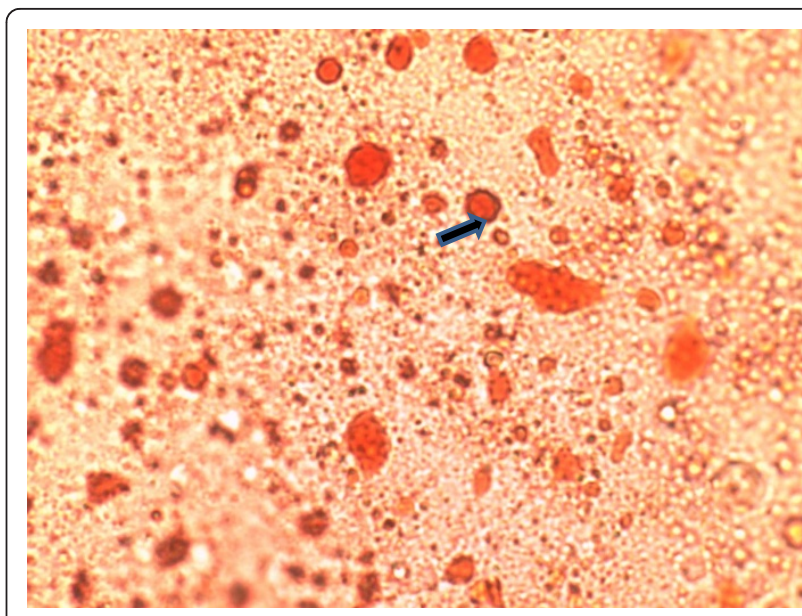

Figure 4 Monocyte (arrow) supplemented with oxLDL and Nigella sativa oil 3 days post-treatment stained with oil red 0 stain and visualized under $400 \times$ light microscope.

respectively. Images of treated cells were captured at 24 hours interval for 3 days as shown in Figure 9, 10, and 11.

The observation on cell growth showed both monocytes and macrophages were larger in size in the presence of oxidized LDL alone for 3 days compared to the combined treatment with Nigella sativa oil and oxidized LDL. There were more cells that differentiated into macrophage-like cells in monocytes supplemented with oxidized LDL alone.

Monocytes were found to be larger in diameter in presence of oxidized LDL throughout the timeline studied compared to the combined treatment of oxidized LDL and Nigella sativa ( $\mathrm{p}<0.001$ ) (see additional file 1 , Table 1). The similar findings were seen in macrophage diameter $(\mathrm{p}<0.001)$ (see additional file 2, Table 2).

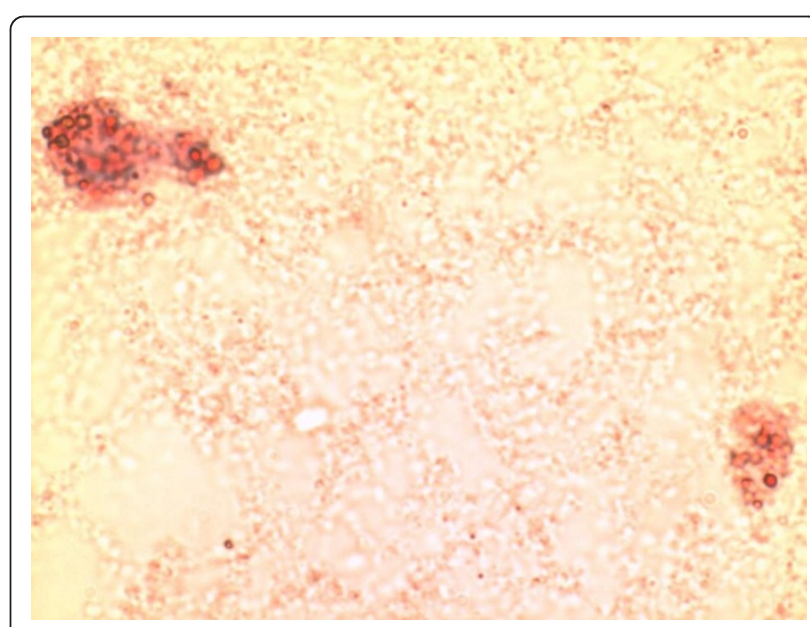

Figure 5 Control primary monocytes-derived macrophage left 3 days untreated visualized under $400 \times$ light microscope. 


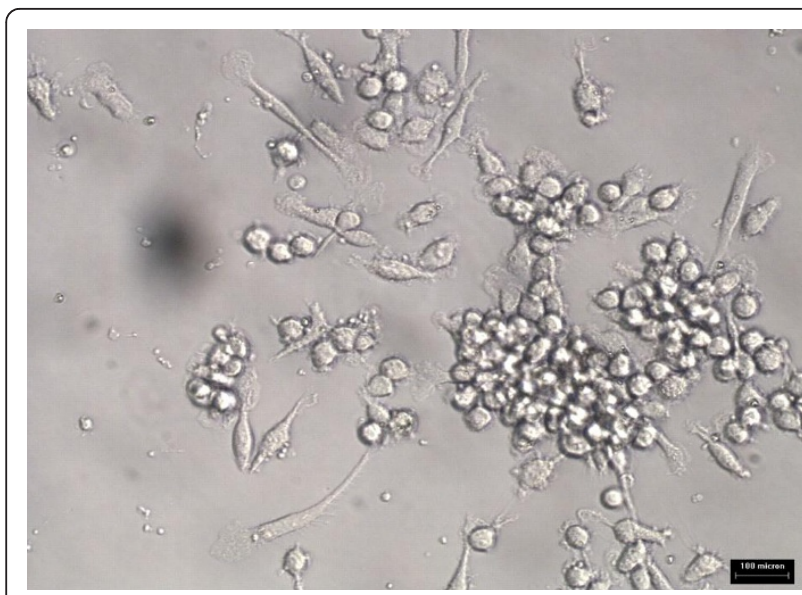

Figure 6 Monocytes/macrophages supplemented with oxidized LDL at 24 hours

Diameter differences in macrophage with combined treatment and treatment with oxidized LDL alone were $12.9 \%$ and $15.2 \%$, respectively. This suggested there was reduced growth in macrophages upon exposure to Nigella sativa oil as shown in Figure 12 and 13. However, monocyte and macrophage showed gradual growth after 48 hours in combined treatment.

\section{Flow cytometry analysis of CD11b expression}

Flow cytometry analysis showed the expression of surface marker CD11b fluorescence intensity of PE stained cells. The finding showed reduction of the fluorescence intensity in monocytes/macrophages treated with combination of Nigella sativa oil and oxidized LDL compared to cells treated with oxidized LDL alone. The differential expression was studied with $100 \mathrm{ng} / \mathrm{ml}$ and $140 \mathrm{ng} / \mathrm{ml}$ Nigella sativa oil treatment. It also included determination of surface antigen CD11b expression in cells supplemented with native LDL, PMA, PMA with oxidized

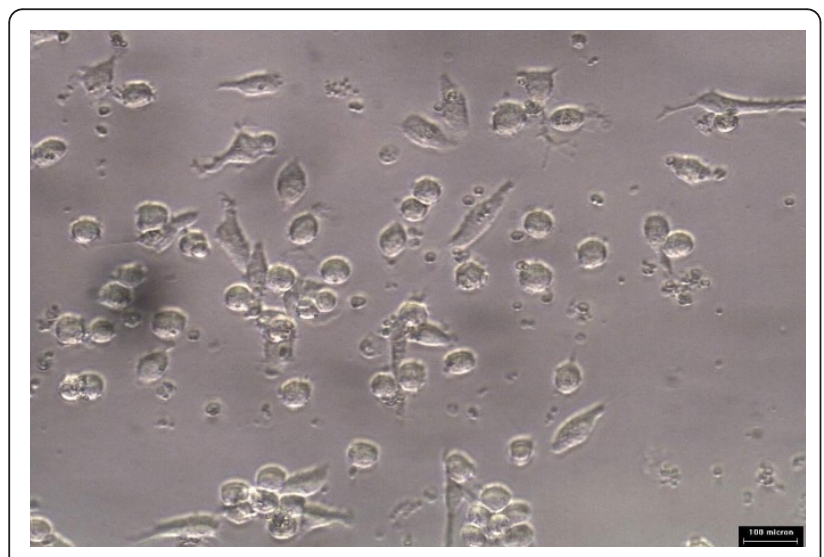

Figure 7 Monocytes/macrophages supplemented with oxidized LDL at 48 hours.

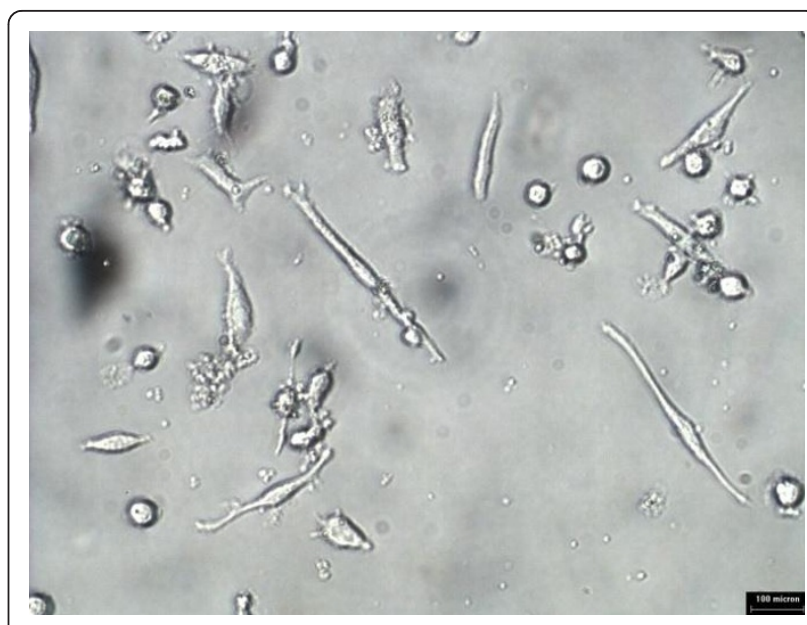

Figure 8 Monocytes/macrophages supplemented with oxidized LDL at 72 hours.

LDL (oxLDL), $140 \mathrm{ng} / \mathrm{ml}$ and $100 \mathrm{ng} / \mathrm{ml}$ Nigella sativa were shown in Figure 14.

\section{Discussion}

Medical plants or products have been related with antiinflammatory properties in cell based studies $[31,32]$. Atherosclerosis is closely related to inflammatory process [33-35]. Among these medical plants is Nigella sativa $\mathrm{L}$, that been reported to contain anti-oxidant and anti-inflammatory properties [36,37]. It acts by inhibiting COX and 5-LO pathways [36]. However, there is limited documentation on effects of Nigella sativa oil towards oxLDL intake in primary human monocyte.

We noted that Nigella sativa oil inhibited growth of monocyte and macrophage cells without causing toxicity. The number of viable cells was reduced to $50 \%$ when treated with $180 \mathrm{ng} / \mathrm{ml}$ Nigella sativa oil. Monocytes

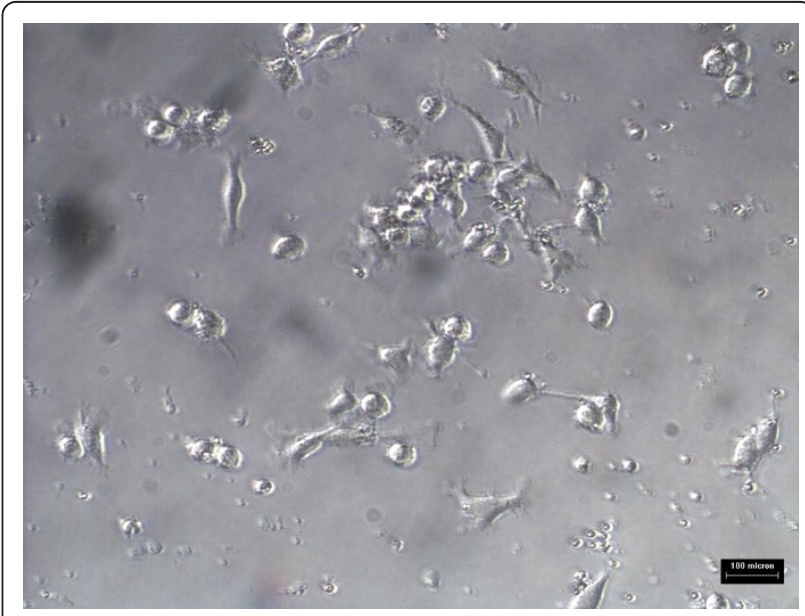

Figure 9 Monocytes/macrophages supplemented with oxidized LDL and Nigella sativa oil at 24 hours. 


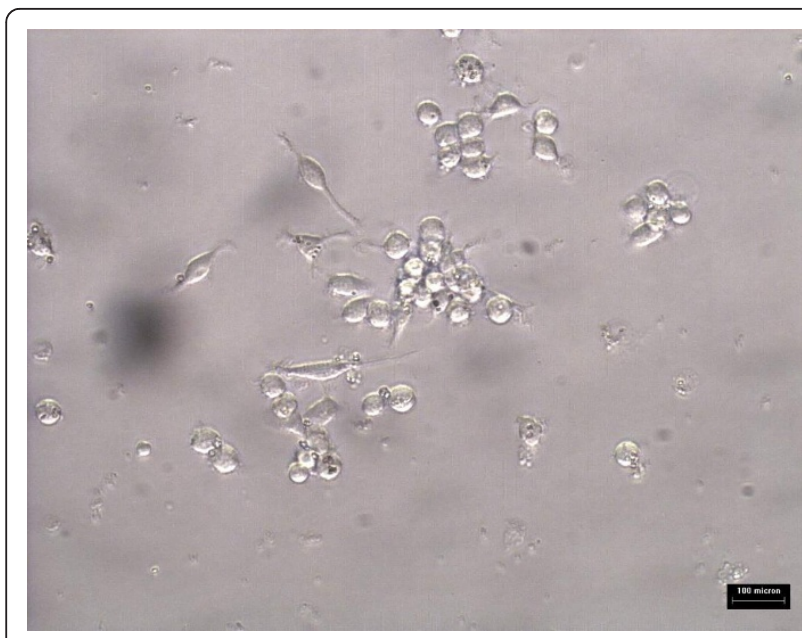

Figure 10 Monocytes/macrophages supplemented with oxidized LDL and Nigella sativa oil at $\mathbf{4 8}$ hours.

were found to be larger in size in the presence of oxidized LDL alone for 3 days compared to combined treatment with Nigella sativa and oxidized LDL. The similar finding was seen in macrophage growth. These findings were consistent with report by Yui et al. [38]. Oxidized LDL was able to induce the growth of murine macrophages in vitro [39]. However, cell growth was found to resume in both monocytes and macrophages after 48 hour. The declined inhibitory effect of Nigella sativa oil could be regulated by daily supplementation of the oil into media. Animal model studies reported daily dose of Nigella sativa caused profound effect in decreasing lipid peroxidation [40,41]. The effect of thymoquinone on proliferation of small cell lung cancer cells was shown to wane with time with less activity observed at 48 and 72 hours, suggesting more frequent dosing may be required to demonstrate a sustained effect [42]. This study showed

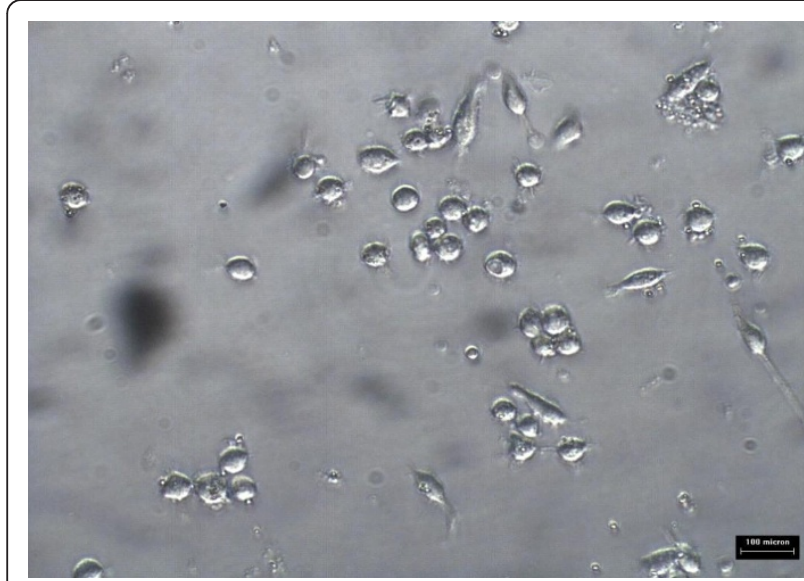

Figure 11 Monocytes/macrophages supplemented with oxidized LDL and Nigella sativa oil at 72 hours.

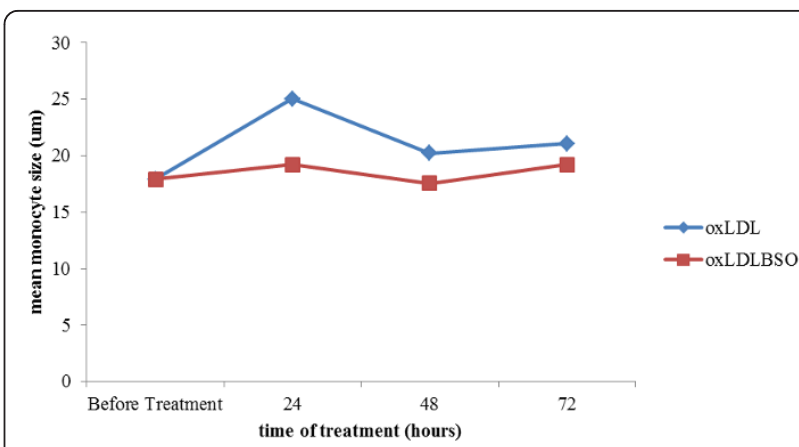

Figure 12 Comparison on mean monocytes size within 3 days of treatment with $10 \mu \mathrm{g} / \mathrm{ml}$ oxidized LDL alone (oxLDL) and combination of $10 \mu \mathrm{g} / \mathrm{ml}$ oxidized LDL with $140 \mathrm{ng} / \mathrm{ml}$ Nigella sativa (oxLDLBSO) with timeline studied.

$140 \mathrm{ng} / \mathrm{ml}$ Nigella sativa oil leads to reduced lipid accumulation within cells and decreased cell growth mainly macrophages within 48 hours treatment. This was in-line to an animal model study where rats were orally fed with Nigella sativa at concentrations of $50 \mathrm{mg} / \mathrm{kg}$ and 100 $\mathrm{mg} / \mathrm{kg}$ body weight and resulted in reduction of lipid peroxidation [43]. It is still unclear whether the cell growth is regulated by expression of enzymes. Over expression of phospholipase A(2) lipolytic has been reported in macrophages, where it strongly increased foam cell formation upon incubation with native LDL and oxLDL [44].

The role of LDL oxidation has been claimed to be fundamental in the formation and progression of early atherosclerosis [45]. Human monocytes-derived macrophages esterified cholesterol from modified LDL more extensively than native LDL [46]. Oxidative modification of LDL can be induced by incubation with cell types like monocyte/macrophage and also other cell types such as endothelial cells and smooth muscle cells as reported by Steinberg [13]. Oxidized LDL is taken up

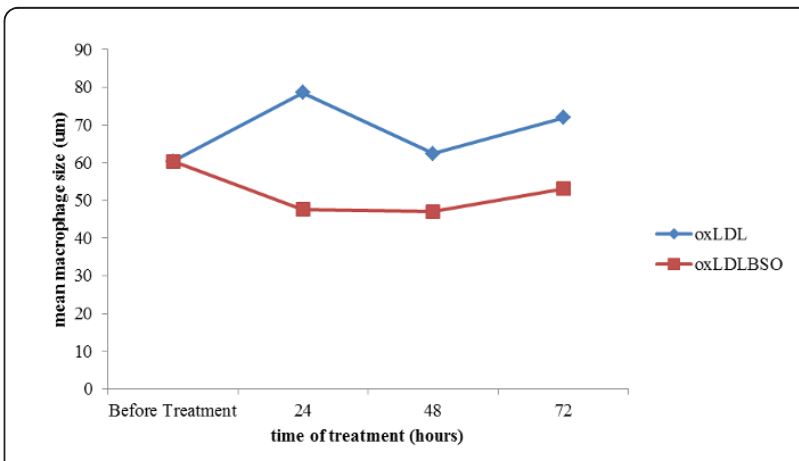

Figure 13 Comparison on mean macrophages size within 3 days of treatment with $10 \mu \mathrm{g} / \mathrm{ml}$ oxidized LDL alone (oxLDL) and combination of $10 \mu \mathrm{g} / \mathrm{ml}$ oxidized LDL with $140 \mathrm{ng} / \mathrm{ml}$ Nigella sativa (oxLDLBSO) with timeline studied. 


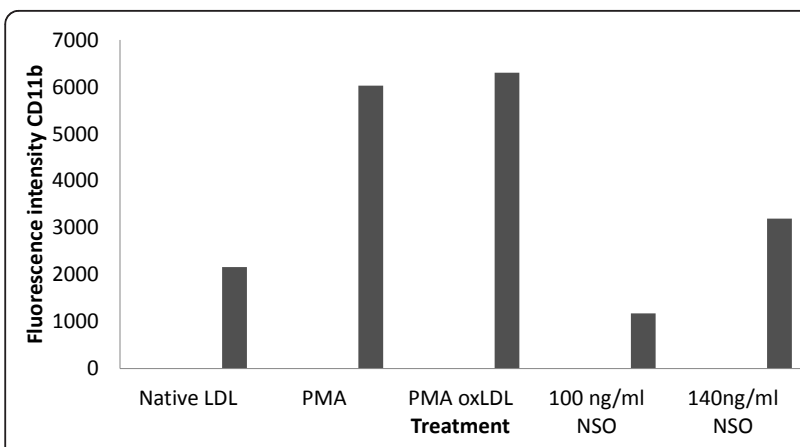

Figure 14 Comparison of CD11b surface marker fluorescence intensity with treatment. PMA = phorbol-myristate-acetate, $L D L=$ low density lipoprotein, oxLDL = oxidized LDL.

rapidly by macrophages scavenger receptors [45]. A number of macrophage cell surface proteins have been identified which include class A scavenger receptor, CD36 and CD68. Fuhrman et al. also reported RAW264.7 murine macrophage cell line treatment with oxidized LDL caused inflammatory response by stimulating replication of monocyte-derived macrophages and entry of new monocyte into lesion [47].

The accumulation of cytoplasmic lipids droplets with oil red $\mathrm{O}$ staining in monocytic cells after exposure to oxidized LDL had been demonstrated [4]. We found treatment with combination of Nigella sativa and oxidized LDL showed no visible intracellular lipid vesicle and the monocyte surface was seen coated with oil red $\mathrm{O}$. In addition, the morphological characteristics did not show significant development of monocyte into macrophage. The cells treated with oxidized LDL alone had intracellular stained lipid in several vesicles. Reduction of lipid stained deposits in combined treatment may be explained by presence of Nigella sativa oil. It may functionally block the oxidized LDL from inducing differentiation of monocyte into macrophages hence blocking the uptake by scavenger receptors. However, the actual mechanism on its action has to be further studied. The lipid deposits in aorta had also been observed in studies to see the effect of Nigella sativa. Animal model study indicated supplementation of either powder or oil form of Nigella sativa to hypercholesterolemic rabbits reduced lipid deposits of intimal surface of aorta indicating inhibition of plaque formation [48].

LDL can also be oxidized by incubation of LDL with a known catalyst of lipid peroxidation, such as copper or iron [49]. Copper was used in the oxidation of LDL in this study. Whereby, heavy oxidation of LDL up to $20 \mu \mathrm{g}$ of protein/ml was used by Fuhrman et al. [47]. They reported that heavy oxidation of LDL was sufficient in inducing differentiation of monocyte into mature macrophages. It has been reported during monocyte to macrophage differentiation the expression of CD11b increased. Oxidized LDL triggers monocyte differentiation into macrophages and induced a distinct peak in fluorescence intensity and increased for sMFI for CD11b [19]. Activated monocytes in patients with active disease of Wegener's Granulomatosis were shown to have an increased surface expression of CD11b when compared to healthy control [50]. It was also shown that together with downregulation of CD11b, the ability of human blood monocytes to phagocytize opsonized E. coli also diminished [51]. These studies provide evidence on the importance of CD11b in the activation of monocytes. Fuhrman et al. found increased expression of CD11b of mouse peritoneal mononuclear cells isolated on 1,2 or 3 day after intra-peritoneal injection of oxidized LDL [47].

The flow cytometry data showed similar expression of cell surface marker, CD11b in monocytes/macrophages when treated with phorbolmyristate acetate (PMA) and oxidized LDL. PMA has been used as an artificial stimulator of monocyte-to-macrophage differentiation [52]. The native LDL did not induce growth of monocyte/ macrophage culture. The cells were spherical and small as reported previously [53].

Differential expression of CD11b with certain doses of Nigella sativa explains its role in primary human monocyte-derived macrophage growth. This was shown by reduced CD 11b expression with $100 \mathrm{ng} / \mathrm{ml}$ Nigella sativa oil compared to $140 \mathrm{ng} / \mathrm{ml}$. However, percentage of cell viability was similar in both these treatments. Further investigation would be carried out to identify the active ingredients found in Nigella sativa oil. It has been report the phytochemical content of Nigella sativa seed differ due to geographical and environmental factors mainly in its phenol and fatty acid contents [54]. Therefore, seeds sown in Malaysia would be characterized in terms of its phytochemical composition. This would provide precise understanding on regulation of monocyte differentiation by the active ingredients.

\section{Conclusions}

Preliminary findings exhibited the presence of $100 \mathrm{ng} /$ ml dilution of Nigella sativa oil caused downregulation in the differentiation of monocytes-to-macrophages based on phenotypic change and CD11b expression. The actual mechanism on how Nigella sativa oil exerts its anti-lipid and CD11b expression effects need to be further investigated.

\section{Methods}

\section{Ethical Approval}

The procedure was subject to approval by the University Ethical Committee. Written consent was obtained from healthy donors without medical history and without drug treatment. Approximately $50 \mathrm{ml}$ of venous blood was collected into EDTA tubes using cannula fixed to vein. 


\section{Primary human monocytes isolation}

The primary cells were isolated using DynabeadsMyPure Monocyte Kit 2 for untouched human cells isolation kit (Invitrogen Dynal AS, Oslo, Norway). The cells were isolated from fresh whole blood collected from donor.

\section{Preparation of Buffer 1}

Buffer 1 contained either $0.1 \%$ bovine serum albumin (BSA) or fetal calf serum (FCS) (Sigma-Aldrich, Germany) and $2 \mathrm{mM}$ EDTA (Invitrogen, USA) in phosphate buffer saline (PBS) (Invitrogen GIBCO, New Zealand) at $\mathrm{pH}$ 7.4. The solution was filter-sterilized with a $0.2 \mu \mathrm{m}$ membrane filter (WhatmanInc., USA) and stored at $4^{\circ} \mathrm{C}$.

\section{Low Density Lipoprotein}

Low density lipoprotein (LDL) was purchased from Milipore (Temecula, California, US). The LDL was isolated by ultracentrifugation method by Milipore and it was used in the study as a negative control.

\section{LDL Oxidation (Oxidized LDL)}

The LDL was diluted in phosphate-buffered saline without EDTA (Invitrogen GIBCO pH 7.4 (1×) Auckland, New Zealand) to $100 \mu \mathrm{g} / \mathrm{ml}$ and dialyzed overnight against PBS at $4^{\circ} \mathrm{C}$ to remove the EDTA. LDL oxidation was done using an incubator shaker (Innova 4080) which was maintained at $37^{\circ} \mathrm{C}$ with 200 rotations per minute. LDL was incubated for 18 hours with the freshly prepared5 $\mathrm{mM} \mathrm{CuSO}_{4}(\mathrm{BDH}$ AnalaR). The oxidation was terminated by refrigeration at $4^{\circ} \mathrm{C}$.

\section{Nigella sativa stock preparation and working solution}

The pressed oil was produced by Baraka Oil Company in Sri Lanka. For the stock preparation, the oil was dissolved in $0.05 \%$ DMSO (Sigma Aldrich Co., USA). To make a preparation of $10 \mathrm{~mL}$ stock, $10 \mu \mathrm{L}$ of Nigella sativa oil was mixed together with $5 \mu \mathrm{L}$ DMSO. The $0.1 \%$ Nigella sativa stock solution was filter-sterilized using $0.2 \mu \mathrm{m}$ membrane filter (Whatman Inc. USA) and stored at $4^{\circ} \mathrm{C}$.

\section{Phorbol 12-Myristate13-Acetate (PMA) preparation}

The Phorbol 12-Myristate13-Acetate (PMA) (Sigma, USA) was dissolved in DMSO and prepared to the concentration of $1 \mathrm{ng} / \mathrm{ml}$. PMA. It was used in this study as a positive control.

\section{Culture Media Preparation}

The RPMI 1640 (GIBCO) medium contained $1 \mathrm{mM} \mathrm{L-}$ glutamine (Sigma-Aldrich, USA), $200 \mathrm{U} / \mathrm{mL}$ pen-strep solution (Invitrogen GIBCO, New Zealand) and 10\% FCS (Sigma-Aldrich, Germany). The FCS was heat-inactivated by preheating at $56^{\circ} \mathrm{C}$ for 30 minutes in waterbath. The media prepared were filter-sterilized with 0.2 $\mu \mathrm{m}$ membrane filter disc (Whatman Inc., USA) and stored at $4^{\circ} \mathrm{C}$.

\section{RPMI 1640 Medium containing 5\% Lipoprotein-deficient serum (LPDS)}

This media was prepared using $1 \mathrm{mM}$ L-glutamine (Sigma-Aldrich Inc., USA), $200 \mathrm{U} / \mathrm{mL}$ pen-strep (Invitrogen GIBCO, New Zealand) and 5\% LPDS (Milipore, USA). The LPDS was used to replace FCS. The media were stored at $4^{\circ} \mathrm{C}$ after being filter-sterilized with 0.2 $\mu \mathrm{m}$ membrane filter disc (WhatmanInc., USA).

\section{Buffy coat preparation}

The buffy coat was prepared from $50 \mathrm{ml}$ of venous blood collected in EDTA tubes. The tubes were centrifuged at $800 \times \mathrm{g}$ for 20 minutes at room temperature $\left(18-24^{\circ} \mathrm{C}\right)$ to obtain the separated layers of plasma, buffy coat and red cells. The supernatant was discarded and buffy coat was isolated from the EDTA tubes and transferred into sterile tube.

\section{Cell isolation using DynabeadsMyPure Monocyte for Untouched Human Cells}

The monocytes were isolated using the DynabeadsMyPure Monocyte isolation kit. The procedure involved isolation of buffy coat from whole blood following centrifugation. A total of 10 to $18 \mathrm{ml}$ of buffy coat was diluted in Buffer 2 to a final volume of $35 \mathrm{ml}$ at 18 to $25^{\circ} \mathrm{C}$ at room temperature. The diluted buffy coat was added on top of $15 \mathrm{ml}$ of lymphoprep (Axis-Shield, POC, Norway) and centrifuged at $160 \times$ g for $20 \mathrm{~min}-$ utes at room temperature. It was allowed to decelerate without brakes. Approximately $20 \mathrm{ml}$ of supernatant was removed to eliminate platelets. Then it was centrifuged at $350 \times \mathrm{g}$ for 20 minutes at room temperature and allowed to decelerate without brakes. The MNC recovered from the plasma and lymphoprep interface was transferred to a $50 \mathrm{ml}$ sterile tube. The MNC was washed once with buffer 1 by centrifugation at $400 \times \mathrm{g}$ for 8 minutes at $2-8^{\circ} \mathrm{C}$ and then washed twice with buffer 1 by centrifugation at $225 \times \mathrm{g}$ for 8 minutes. The MNC was suspended at $1 \times 10^{7} \mathrm{MNC}$ per $\mathrm{ml}$ in Buffer 1. A total of $100 \mu \mathrm{l} \mathrm{MNC}$ in Buffer 1 was transferred to a tube and $20 \mu \mathrm{l}$ of blocking reagent and antibody mix were added separately. This was mixed well and incubated for 20 minutes at $2-8^{\circ} \mathrm{C}$. The cells were washed by adding $2 \mathrm{ml}$ buffer 1 and mixed by tilting the tube several times before centrifugation at $300 \times \mathrm{g}$ for 8 minutes at $2-8^{\circ} \mathrm{C}$. The supernatant was discarded and cells were suspended in $900 \mu \mathrm{l}$ Buffer 1 (which was pre-cooled to $\left.2-8^{\circ} \mathrm{C}\right)$. A volume of $100 \mu \mathrm{l}$ of pre-washed Depletion MyOneDynabeads was added and mixed well before incubation for 15 minutes at $2-8^{\circ} \mathrm{C}$ by gentle tilting and rotation. The bead-bound cells were re-suspended by 
vigorous pipetting 5 times using a narrow tip opening. Then, $1 \mathrm{ml}$ of pre-cooled buffer 1 was added and tube was place in the Dynal MPC-L (DynalMag 15) (Invitrogen, GIBCO, New Zealand) for 3 minutes. The supernatant was transferred to a new tube and placed again in the magnet for another 3 minutes. The supernatant obtained following these steps contained approximately $1 \times 10^{7}$ of untouched human monocytes.

\section{Culture growth}

The platelet-free monocytes were resuspend in $5 \mathrm{ml}$ RPMI 1640 supplemented with L-glutamine $1 \mathrm{mM}, 200$ $\mathrm{U} / \mathrm{ml}$ penicillin-streptomycin and $5 \%$ heat-inactivated fetal calf or bovine serum. The cells were incubated in a humidified incubator with $5 \% \mathrm{CO}_{2}$ and $95 \%$ air.

\section{Staining Methods}

There are two types of cell staining methods were applied in the study. Wright's staining was done as confirmatory staining for monocytes. The oil red $\mathrm{O}$ stain was used to visualize cholesterol ester deposition in the monocytes.

\section{Wright's staining}

The Wright stain was used for the air-dried smear. It produced the typical purple coloration of nuclei and neutrophilic granules. Methyl alcohol is used both as a solvent and fixative in this procedure. The nucleus and cytoplasm expanded after staining. The smear was immersed with Wright's solution for 4 minutes and followed by phosphate buffer solution for additional 9 minutes. Smear is then washed with water and air-dried. Finally, Cytoseal XYL was used for mounting of smear.

\section{Oil red $O$ staining}

Oil Red $\mathrm{O}$ is a lysochrome (fat-soluble dye) diazo dye used for staining of neutral triglycerides and lipids on frozen sections and some lipoproteins on paraffin sections. Oil Red O staining has to be performed on fresh samples as alcohol fixation removes the lipid. Oil Red O staining was used to view deposition of oxidized LDL in monocytes treated with oxidized LDL alone or oxidized LDL in the presence of Nigella sativa oil. The cell solution was air-dried on a slide before staining. A solution was prepared with 3 parts of $0.1 \%$ oil red $\mathrm{O}$ in isopropyl alcohol mixed with 2 parts of water. The slide was immersed into oil red $\mathrm{O}$ solution for 20 minutes and then dipped few times in $60 \%$ ethyl alcohol to clear the background. Staining was continued with Harris hematoxylin and then the slide was placed under running water. It was rinsed with distilled water and mounted with glycerin jelly. Fat component was stained deep red or deep orange, nuclei stained blue and other structures were unstained. The staining with Wright stain and oil red $\mathrm{O}$ stain for samples were done in duplicates.

\section{Nigella sativa oil toxicity}

Cell viability was done using trypan blue dye (GIBCO/ BRL) exclusion to determine the optimum concentration of Nigella sativa oil. The concentrations of Nigella sativa oil studied were $180 \mathrm{ng} / \mathrm{ml}, 140 \mathrm{ng} / \mathrm{ml}, 100 \mathrm{ng} /$ $\mathrm{ml}, 70 \mathrm{ng} / \mathrm{ml}$ and $35 \mathrm{ng} / \mathrm{ml}$. The number of viable cells was determined using hemacytometer. The cells were trypsinized before treatment with the trypan blue dye. A $20 \mu \mathrm{l}$ of the suspension was collected and placed on a clean surface. Then, $20 \mu$ l of trypan blue dye (GIBCO, BRL) was added to the cell suspension and mixed before transferred to the edge of the haemocytometer slide and covered by a cleaned coverslip (The hemacytometer was earlier cleaned with $70 \%$ ethanol). The suspension mixture will automatically be drawn under the coverslip by capillarity. Any surplus fluid was then blotted and the slide was viewed under an inverted microscope. The cells were counted within the four corners of the grid. Both viable and non-viable cells were counted. The non-viable cells were stained blue. The total volume of the cells was then calculated using the formula given.

Cell counting formula:

$$
\mathrm{C}=\mathrm{Av} \times 2^{*} \times 10^{4} \text { cells } / \mathrm{ml}
$$

Where; $\mathrm{C}=$ cell concentration $($ cell $/ \mathrm{ml})$

Av $=$ average number of cells in four corners counted

$$
2^{*}=\text { dilution factor }
$$

Percentage of viable cells was counted as in the following formula:

$$
\text { Percentage of viability }(\%)=\mathrm{Nv} / \mathrm{Nt} \times 100
$$

Where; $\mathrm{Nv}=$ number of viable cells

$$
\mathrm{Nt}=\text { number of cell population }
$$

\section{Uptake of oxidized lipoprotein}

The cells were grown till confluence in RPMI 1640 media. The adherent cells were transferred from $25-\mathrm{ml}$ culture flask and centrifuged at $220 \times \mathrm{g}$ for 8 minutes at $2-8^{\circ} \mathrm{C}$. The cells were then plated in 24 well plate and supplemented with RMPI 1640 that contained 5\% lipoprotein-deficient serum LPDS in replacement of FBS. Then cells were left to grow until complete adherence in humidified condition with $5 \% \mathrm{CO}_{2}$ incubator at $37^{\circ} \mathrm{C}$. The modulator effect of Nigella sativa on uptake of 
oxidized low density lipoprotein was studied by using $140 \mathrm{ng} / \mathrm{ml}$ of Nigella sativa oil. The study design comprised supplementation with oxidized LDL $(10 \mu \mathrm{g} / \mathrm{ml})$ alone and combination of oxidized LDL $(10 \mu \mathrm{g} / \mathrm{ml})$ and Nigella sativa oil $(140 \mathrm{ng} / \mathrm{ml})$. The microscopic images of the cells were taken at every 24 hours interval for 3 days.

\section{Microscopic analysis}

The monocyte growth images were recorded using inverted phase-contrast microscope Axiovert 25 (ZEISS) pre-treatment, post-treatment day-1 and post-treatment day-5. The cells were stained using oil red $\mathrm{O}$ to visualize lipid engorgement into cells. The growth was determined based on cell diameter using Pro-plus software and type with positive staining of oil red $\mathrm{O}$. Growth rate was determined based on difference in cell diameter before and after treatment.

\section{Flow cytometry analysis}

Sample was prepared for cell surface antigen detection, CD11b using flow cytometry analysis by FACS Canto analyzer. The surface marker CD11b was detected using monoclonal antibody (BD Biosciences. San Jose36-37, Canada) reacted against $\mathrm{CD} 11 \mathrm{~b}$ antigen on monocyte surfaces. Analysis was done using software FACS Diva Version 6.1.2.

The sample preparation was done by isolating at least $1 \times 10^{4}$ cells into a $15 \mathrm{ml}$ conical tube. The tube was centrifuged and media was removed to leave the cell pellets. The cells were then washed once with PBS at $\mathrm{pH}$ 7.4. This was followed by addition of $20 \mathrm{ug}$ of CD11b monoclonal antibodies (BD Biosciences, Canada) into the tube and the tube was then incubated for 30 minutes in a dark place. After incubation the samples were washed again twice with PBS to remove excess antibody. The cells were then suspended in PBS for flow cytometry analysis.

Expression of surface marker CD11b was studied within 72 hours. The data obtained on 10,000 cells were stored in list-mode data files and analyzed by FACS Diva Version 6.1.2 software. The instrument was calibrated using CST Setup Beads (BD Biosciences, San Jose, CA). Monocyte subpopulation gating was based on forward scatter versus side scatter plot. To confirm the monocyte subpopulation, PE CD11b against side scatter was plotted.

The test samples included negative control (native LDL), positive controls (PMA, PMA with oxLDL), cells treated with $100 \mathrm{ng} / \mathrm{ml}$ dilution of Nigella sativa oil and treated with $140 \mathrm{ng} / \mathrm{ml}$ of Nigella sativa oil as shown in Figure 3, 4, 5, 6, 7, 8 .

\section{Statistical analysis}

Each experiment was done in triplicates. Analysis of results was done using t-test. All values were expressed as means \pm standard deviation. Values of $\mathrm{p}<0.05$ were considered as significant.

\section{Additional material}

Additional file 1: Mean differences in monocyte growth. (Results were expressed as mean \pm s.d. $p<0.001$ indicates statistically significant different. The experiments were done in triplicates). $\mathrm{OxLDL}=$ oxidized LDL, OxLDLNSO = oxidized LDL combined with NSO, Mean = mean diameter of cells in $\mu \mathrm{m}$.

Additional file 2: Mean differences in macrophage growth. (Results were expressed as mean \pm s.d. $p<0.001$ indicates statistically significant different. The experiments were done in triplicates). OxLDL = oxidized $\mathrm{LDL}, \mathrm{OxLDLNSO}=$ oxidized $\mathrm{LDL}$ combined with $\mathrm{NSO}$, Mean $=$ mean diameter of cells in $\mu \mathrm{m}$.

\section{Acknowledgements}

This study was supported by Universiti Sains Malaysia short term grant 304/ PPSP/6131530. We would like to thank Department of Immunology, Central Research Laboratory, Anatomy Department and Pathology Department at School of Medical Sciences, and Craniofacial Laboratory at School at Dental Sciences for providing facilities and support to conduct this research. We also would like to express our gratitude to the statistician.

\section{Author details}

'Department of Chemical Pathology, School of Medical Sciences, Universiti Sains Malaysia, 16510 KubangKerian, Kelantan, Malaysia. ${ }^{2}$ Advanced Medical and Dental Institute, Universiti Sains Malaysia, Lot 1-8, PersiaranSeksyen 4/1, Bandar Putra Bertam, Kepala Batas 13200, Penang, Malaysia.

\section{Authors' contributions}

SSH and ASM were involved in the designing of the study. $\mathrm{MCH}$ and $\mathrm{SSH}$ participated in recruited of volunteer, isolation, identification and analyses. ASM contributed the antibody for flow cytometry and toxicity analysis. The manuscript was written by $\mathrm{MCH}$. All authors have reviewed and approved the manuscript.

\section{Competing interests}

The authors declare that they have no competing interests.

Received: 28 September 2011 Accepted: 21 November 2011

Published: 21 November 2011

\section{References}

1. Chin S, Jeyaindran S, Azhari R, Wan Azman W, Omar I, Robaayah Z, Sim K. Acute Coronary Syndrome (ACS) Registry - Leading the charge for National Cardiovascular Disease (NCVD) Database. Med J Malaysia 2008, 63(Supplemen C):29-36.

2. Zambahari R: Trends in cardiovascular disease and risk factors in Malaysia. International Congress Series 2004, 1262:446-449.

3. Dollery CM, Libby P: Atherosclerosis and proteinase activation. CardiovasC Res 2006, 69(3):625-635.

4. Nagy L, Tontonoz P, Alvarez JGA, Chen H, Evans RM: Oxidized LDL Regulates Macrophage Gene Expression through Ligand Activation of PPAR $^{3}$. Cell 1998, 93(2):229-240

5. Steinberg D: Atherogenesis in perspective: Hypercholesterolemia and inflammation as partners in crime. Nat Med 2002, 8:1211-1217.

6. Toshima S, Hasegawa A, Kurabayashi M, Itabe H, Takano T, Sugano J, Shimamura K, Kimura J, Michishita I, Suzuki T, et al: Circulating oxidized low density lipoprotein levels. A biochemical risk marker for coronary heart disease. Arterioscler Thromb Vasc Biol 2000, 20(10):2243-2247. 
7. Krieger $\mathrm{M}$ : The other site of scavenger receptors. Pattern recognition and host defense. Curr Opin Lipidology 1997, 8:275-280.

8. Osterud B, Bjorklid E: Role of Monocytes in Atherogenesis. Physiol Rev 2008, 83:1069-1112.

9. Osterud B, Bjorklid E: Role of monocytes in atherogenesis. Physiol Rev 2003, 83(4):1069-1112.

10. Berliner JA, Navab M, Fogelman AM, Frank JS, Demer LL, Edwards PA, Watson AD, Lusis AJ: Atherosclerosis: basic mechanisms. Oxidation, inflammation, and genetics. Circulation 1995, 91(9):2488-2496.

11. Brown MS, Goldstein JL: A receptor-mediated pathway for cholesterol homeostasis. Science 1986, 232(4746):34-47.

12. Chisolm GM, Hazen SL, Fox PL, Cathcart MK: The oxidation of lipoproteins by monocytes-macrophages. Biochemical and biological mechanisms. J Biol Chem 1999, 274(37):25959-25962.

13. Steinberg D: Lewis A. Conner Memorial Lecture. Oxidative modification of LDL and atherogenesis. Circulation 1997, 95(4):1062-1071.

14. Witztum JL, Steinberg D: Role of oxidized low density lipoprotein in atherogenesis. J Clin Invest 1991, 88(6):1785-1792.

15. Pasini AF, Anselmi M, Garbin U, Franchi E, Stranieri C, Nava MC, Boccioletti V, Vassanelli C, Cominacini L: Enhanced Levels of Oxidized Low-Density Lipoprotein Prime Monocytes to Cytokine Overproduction via Upregulation of CD14 and Toll-Like Receptor 4 in Unstable Angina. Arterioscler Thromb Vasc Biol 2007, 27(9):1991-1997.

16. Fuhrman B, Shiner M, Volkova N, Aviram M: Cell-induced copper ionmediated low density lipoprotein oxidation increases during in vivo monocyte-to-macrophage differentiation. Free Radic Biol Med 2004, 37(2):259-271

17. Anderson DC, Springer TA: Leukocyte adhesion deficiency: an inherited defect in the Mac-1, LFA-1, and p150,95 glycoproteins. Annu Rev Med 1987, 38:175-194.

18. Stoneman V, Braganza D, Figg N, Mercer J, Lang R, Goddard M, Bennett M: Monocyte/macrophage suppression in CD11b diphtheria toxin receptor transgenic mice differentially affects atherogenesis and established plaques. Circ Res 2007, 100(6):884-893.

19. Weber C, Erl W, Weber PC: Enhancement of monocyte adhesion to endothelial cells by oxidatively modified low-density lipoprotein is mediated by activation of CD11b. Biochem Biophys Res Commun 1995, 206(2):621-628.

20. Vuorelaa P, Leinonenb M, Saikkuc P, Tammelaa P, Rauhad JP, Wennberge T, Vuorela $\mathrm{H}$ : Natural products in the process of finding new drug candidates. Curr Med Chem 2004, 11(11):1375-1389.

21. Ali BH, Blunden G: Pharmacological and toxicological properties of Nigella sativa. Phytother Res 2003, 17(4):299-305.

22. Al-Ghamdi MARaMS: A review of the pharmaco-therapeutic effects of Nigella sativa. Pakistan Journal of Medical Research 2002, 41(2):77-83.

23. El Tahir KEH, Ashour MMS, Al-Harbi MM: The cardiovascular actions of the volatile oil of the black seed (Nigella sativa) in rats: elucidation of the mechanism of action. General Pharmacology: The Vascular System 1993, 24(5):1123-1131.

24. Gali-Muhtasib H, Roessner A, Schneider-Stock R: Thymoquinone: a promising anti-cancer drug from natural sources. Int J Biochem Cell Biol 2006, 38(8):1249-1253.

25. El-Bahai MN, Al-Hariri MT, Yar T, Bamosa AO: Cardiac inotropic and hypertrophic effects of Nigella sativa supplementation in rats. Int $J$ Cardiol 2009, 131(3):e115-117.

26. Michelsen KS, Doherty TM, Shah PK, Arditi M: TLR signaling: an emerging bridge from innate immunity to atherogenesis. J Immunol 2004, 173(10):5901-5907.

27. Majdalawieh AF, Hmaidan R, Carr Rl: Nigella sativa modulates splenocyte proliferation, Th1/Th2 cytokine profile, macrophage function and NK anti-tumor activity. Journal of Ethnopharmacology 2010, 131(2):268-275.

28. El-Mahmoudy A, Matsuyama H, Borgan MA, Shimizu Y, El-Sayed MG, Minamoto N, Takewaki T: Thymoquinone suppresses expression of inducible nitric oxide synthase in rat macrophages. International Immunopharmacology 2002, 2(11):1603-1611.

29. Fararh KM, Atoji Y, Shimizu Y, Shiina T, Nikami H, Takewaki T: Mechanisms of the hypoglycemic and immunopotentiating effects of Nigella sativa L. oil in streptozocin-induced diabetic hamsters. Res Vet Sci 2004, 77:123-129.
30. Al-Naqeep G, Ismail M, Al-Zubairi A: Fatty Acid Profile, alpha-tocopherol and total antioxidant activity of extracted form Nigella sativa seeds. Int J Pharmacol 2009, 5:244-250

31. Liu Q, Shu X, Wang L, Sun A, Liu J, Cao X: Albaconol, a plant-derived small molecule, inhibits macrophage function by suppressing NF-kappaB activation and enhancing SOCS1 expression. Cell Mol Immunol 2008, 5(4):271-278.

32. Nakamura T, Kodama N, Arai Y, Kumamoto T, Higuchi Y, Chaichantipyuth C, Ishikawa T, Ueno K, Yano S: Inhibitory effect of oxycoumarins isolated from the Thai medicinal plant Clausena guillauminii on the inflammation mediators, iNOS, TNF-alpha, and COX-2 expression in mouse macrophage RAW 264.7. J Nat Med 2009, 63(1):21-27.

33. Loppnow $H$, Werdan $K$, Buerke M: Vascular cells contribute to atherosclerosis by cytokine- and innate-immunity-related inflammatory mechanisms. Innate Immun 2008, 14(2):63-87.

34. Wang L, Geng C, Jiang L, Gong D, Liu D, Yoshimura H, Zhong L: The antiatherosclerotic effect of olive leaf extract is related to suppressed inflammatory response in rabbits with experimental atherosclerosis. Eur 」 Nutr 2008, 47(5):235-243.

35. Bechara C, Chai H, Lin PH, Yao Q, Chen C: Growth related oncogene-alpha (GRO-alpha): roles in atherosclerosis, angiogenesis and other inflammatory conditions. Med Sci Monit 2007, 13(6):RA87-90.

36. Salem ML: Immunomodulatory and therapeutic properties of the Nigella sativa L. seed. Int Immunopharmacol 2005, 5(13-14):1749-1770.

37. Randhawa MA, Al-Ghamdi MS: A review on the pharmacotherapeutic effects of Nigella sativa. Pakistan J Med Res 2002, 41(2):1-10.

38. Yui S, Sasaki T, Miyazaki A, Horiuchi S, Yamazaki M: Induction of murine macrophage growth by modified LDLs. Arterioscler Thromb 1993, 13(3):331-337.

39. Shen LH, Zhou L, Wang BY, Pu J, Hu LH, Chai DJ, Wang L, Zeng JZ, He B: Oxidized low-density lipoprotein induces differentiation of RAW264.7 murine macrophage cell line into dendritic-like cells. Atherosclerosis 2008, 199(2):257-264.

40. Kanter M, Coskun O, Budancamanak M: Hepatoprotective effects of Nigella sativa $L$ and Urtica dioica $L$ on lipid peroxidation, antioxidant enzyme systems and liver enzymes in carbon tetrachloride-treated rats. World J Gastroenterol 2005, 11(42):6684-6688.

41. Meral I, Yener Z, Kahraman T, Mert N: Effect of Nigella sativa on glucose concentration, lipid peroxidation, anti-oxidant defence system and liver damage in experimentally-induced diabetic rabbits. J Vet Med A Physiol Pathol Clin Med 2001, 48(10):593-599.

42. Jafri SH, Glass J, Sui R, Zhang S, Prince M, Kleiner-Hancock H: Thymoquinone and cisplatin as a therapeutic combination in lung cancer. J Exp Clin Cancer Res 2010, 29(1):87-95.

43. Khan N, Sultana S: Inhibition of two stage renal carcinogenesis, oxidative damage and hyperproliferative response by Nigella sativa. Eur I Cancer Prev 2005, 14(2):159-168.

44. Curfs DM, Ghesquiere SA, Vergouwe MN, van der Made I, Gijbels MJ, Greaves DR, Verbeek JS, Hofker MH, de Winther MP: Macrophage secretory phospholipase A2 group X enhances anti-inflammatory responses, promotes lipid accumulation, and contributes to aberrant lung pathology. J Biol Chem 2008, 283(31):21640-21648.

45. Steinberg D, Parthasarathy S, Thomas C, Khoo E, John C, Witztum JL: Beyond Cholesterol: Modification of Low-Density Lipoprotein That Increase Its Atherogenecity. New England Journal of Medicine 1989, 320(14):915-924

46. Heinecke JW, Rosen H, Chait A: Iron and copper promote modification of low density lipoprotein by human arterial smooth muscle cells in culture. J Clin Invest 1984, 74(5):1890-1894.

47. Fuhrman B, Partoush A, Volkova N, Aviram M: Ox-LDL induces monocyteto-macrophage differentiation in vivo: Possible role for the macrophage colony stimulating factor receptor (M-CSF-R). Atherosclerosis 2008, 196(2):598-607.

48. Al-Naqeep G, Al-Zubairi AS, Ismail M, Amom ZH, Esa NM: Antiatherogenic Potential of Nigella sativa Seeds and Oil in Diet-Induced Hypercholesterolemia in Rabbits. eCAM, neq071.

49. Steinbrecher UP, Parthasarathy S, Leake DS, Witztum JL, Steinberg D: Modification of low density lipoprotein by endothelial cells involves lipid peroxidation and degradation of low density lipoprotein phospholipids. 
Proceedings of the National Academy of Sciences of the United States of America 1984, 81(12):3883-3887.

50. Muller Koboid AC, Kakenberg CGM, Tervaet JWC: Monocyte activation in patients with Wegener's granulomatosis. Ann Rheum Dis 1999, 58:237-245.

51. Spittler A, Willheim M, Leutmezer F, Ohler R, Krugluger W, Reissner C, Lucas S, Brodowicz T, Roth E, Boltznitulescu G: Effects of 1alpha,25dihydroxyvitamin $\mathrm{D}_{3}$ and cytokines on the expression of MHC antigens, complement receptors and other antigens on human blood monocytes and U937 cells: role in cell differentiation, activation and phagocytosis. Immunology 1997, 90(2):286-293.

52. Auwerx J, Staels B, Van Vaeck F, Ceuppens JL: Changes in IgG Fc receptor expression induced by phorbol 12-myristate 13-acetate treatment of THP-1 monocytic leukemia cells. Leuk Res 1992, 16(3):317-327.

53. Yui S, Sasaki T, Miyazaki A, Horiuchi S, Yamazaki M: Induction of murine macrophage growth by modified LDLs. Arterioscler Thromb Vasc Biol 1993, 13(3):331-337.

54. Salma Cheikh-Rouhou SB, Hentati Basma, Blecker Christophe, Deroanne Claude, Hamadi Attia Nigella sativa L: Chemical composition and physicochemical characteristics of lipid fraction. Food Chemistry 2007, 101(2):673-681.

doi:10.1186/1476-511X-10-216

Cite this article as: Mat et al:: Primary human monocyte differentiation regulated by Nigella sativa pressed oil. Lipids in Health and Disease 2011 10:216.

\section{Submit your next manuscript to BioMed Central and take full advantage of:}

- Convenient online submission

- Thorough peer review

- No space constraints or color figure charges

- Immediate publication on acceptance

- Inclusion in PubMed, CAS, Scopus and Google Scholar

- Research which is freely available for redistribution

Submit your manuscript at www.biomedcentral.com/submit 